\title{
Tribute to Günter Gauglitz
}

\section{Frieder W. Scheller}

Published online: 19 February 2009

(C) Springer-Verlag 2008

This tribute is dedicated to Günter Gauglitz, one of the leading scientists in Analytical Chemistry in Germany and abroad, on the occasion of his 65th birthday.

Günter Gauglitz was born 1944 in Mährisch-Ostrau (now Czech Republic). He received his doctorate in chemistry at the University of Tübingen in 1972. In 1987 he became a Professor in Physical Chemistry and in 1988 a Full Professor for Analytical Chemistry and Informatics at Tübingen University.

Since 2000 Günter Gauglitz has chaired Commission V.4 of IUPAC and since 2001 he has been one of the editors of 'Analytical and Bioanalytical Chemistry'. He is chairman of the Chemometrics and Laboratory Data Processing Section of the German Chemical Society and also serves on many other scientific committees.

In 2006 he was awarded the Pregl Medal by the Austrian Society for Analytical Chemistry.

Günter Gauglitz has written more than 200 scientific articles and authored or co-authored several monographs.

In Germany Günter Gauglitz is the pioneer in optical biosensors and he has brought to perfection the "opt(r)ode"

F. W. Scheller $(\bowtie)$

University of Potsdam, Chair in Analytical Biochemistry,

Karl-Liebknecht-Str. 24-25,

14476 Potsdam-Golm, Germany

e-mail: fschell@uni-potsdam.de

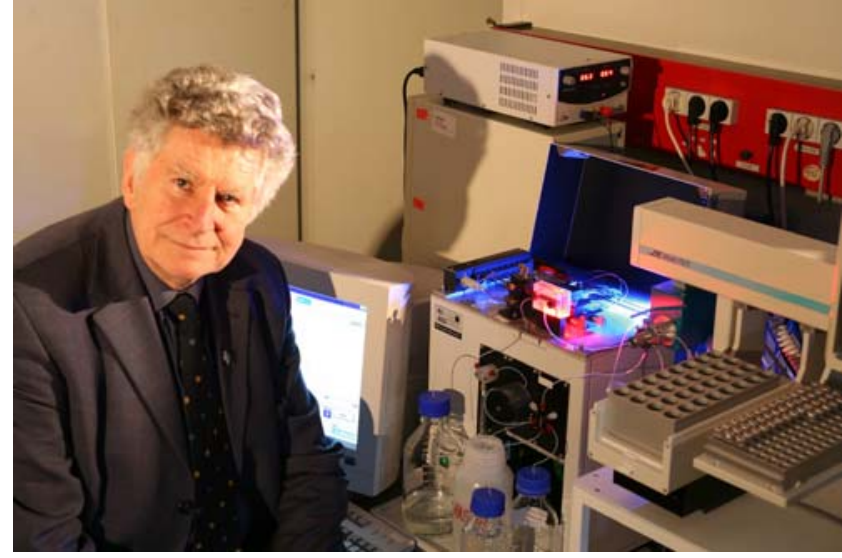

Günter Gauglitz

originally created by Lübbers. His institute in Tübingen has brought forth a large family of sensor siblings that now work in many German universities and companies.

In the early years of his career he did not work with sensors but performed photochemical investigations. However, data evaluation and sample recognition already played an important role then. His habilitation thesis written in 1979 dealt with the photostability of laser dyes. Optical sensors appeared - with a question mark - in the title of one of his papers (Optical Sensors, do they Require a Computer?) for the first time in 1991. At the 1st AllGerman Biosensor Meeting in Bogensee (May 1991) he 
announced that from then on he would be working on affinity sensors based on interferrometry. After a short interlude with enzymatic sensors affinity sensors became the core of further developments. In addition to miniaturizing and improving the sensitivity of sensors the development of sensor arrays began. Investigations concentrated on immuno-sensors and over the past few years his work has also included nucleic acids and molecularly imprinted polymers.

Günter Gauglitz is one of the founding fathers of the German Biosensor Symposia and has greatly added to the success of these meetings which focus on up-andcoming young scientists. For many years he has chaired the Analytical Chemistry Section in the German Chemical Society, organised the Europtrode meetings and coorganised the biennial Analytica Conferences thus adding to the reputation of our field. His work as an editor of Analytical and Bioanalytical Chemistry has essentially contributed to the growing reputation of this journal.

Dear Günter, let me close my remarks by thanking you for many years of friendly cooperation and by wishing you all the best for the years to come. 